\title{
Стратегические альянсы
}

\section{и партнерские программы в новой экономике: опыт российской и мировой IT-отрасли}

\author{
Д.С. Пащенко ${ }^{a}$ Н.М. Комаров \\ а независимый консультант в области разработки программного обеспечения, Москва, Россия \\ ь ФГУП «ЦНИИ «ЦЕНТР», Москва, Россия

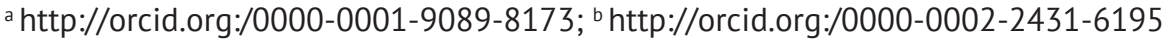

\begin{abstract}
АННОТАЦИЯ
Компании из отраслей новой экономики быстро адаптируют традиционные методы повышения эффективности бизнеса, в том числе связанные с экономической интеграцией, с другими участниками рынка. В ІТ-отрасли партнерские программы и стратегические альянсы стали ключевыми факторами в конкурентной борьбе, их число превысило аналогичный показатель отраслей традиционной экономики. При этом в построении таких экономических интеграций следует учитывать специфические отраслевые особенности, которые накладываются на стремительное изменение ожиданий участников рынка. В статье описаны типичные партнерские программы и стратегические альянсы в ІТ-отрасли, приведены классификации и примеры из области российского и мирового рынка разработки программного и аппаратного обеспечения и системной интеграции. Также в работе проанализированы ключевые отраслевые особенности, показано их влияние на структуру затрат участников и скорость принятия стратегических решений в области развития бизнеса. В заключение статьи сформулирована взаимосвязь типичных экономических интеграций в отрасли: от партнерской программы до слияния (поглощения).

Ключевые слова: партнерская программа; стратегический альянс; IT-отрасль; слияния и поглощения
\end{abstract}

Для цитирования: Пащенко Д.С., Комаров Н.М. Стратегические альянсы и партнерские программы в новой экономике: опыт российской и мировой IT-отрасли. Мир новой экономики. 2020;14(1):15-25. DOI: 10.26794/2220-64692020-14-1-15-25

\section{Strategic Alliances and Partnership Programs in the New Economy: Russian and Global Experience in the IT Industry}

\author{
D.S. Paschenko a N.M. Komarov ${ }^{b}$ \\ ${ }^{a}$ an independent consultant in the field of software development, Moscow, Russia \\ ${ }^{\mathrm{b}} \mathrm{CNII}$ Center, Moscow, Russia \\ a http://orcid.org:/0000-0001-9089-8173; ' ${ }^{\text {h }}$ ttp:// orcid.org:/0000-0002-2431-6195
}

\begin{abstract}
Companies from the "new" economy are quickly adapting traditional methods and approaches to increase business efficiency, including economic integrations with other market participants. In the IT industry partnership programs and strategic alliances have become the critical factors in the competition. At the same time, there are a lot of specific industry features in the construction of those economic integrations, related to rapid change in the expectations of market participants. The article describes typical partnership programs and strategic alliances in the IT industry, gives
\end{abstract}

(c) Пащенко Д.С., Комаров Н.М., 2020 
classifications and examples from the Russian and Global markets for software and hardware development and system integration. The paper also analyses essential industry specifics, shows their impact on the cost structure of participants and the speed of strategic decisions in the field of business development. The article defines a relationship between typical economic integrations in the industry: from affiliate programs to M\&A deals.

Keywords: affiliate program; partnership program; strategic alliance; IT industry; mergers and acquisitions

For citation: Paschenko D.S., Komarov N.M. Strategic alliances and partnership programs in the new economy: Russian and global experience in the IT industry. Mir novoi ekonomiki = The World of the New Economy. 2020;14(1):15-25. DOI: 10.26794/2220-6469-2020-14-1-15-25

\section{ВВЕДЕНИЕ И ПОСТАНОВКА ПРОБЛЕМЫ}

Современная ІТ-отрасль имеет сравнительно короткую историю развития и сосредотачивает в себе значительные интеллектуальные и финансовые ресурсы. Неудивительно, что компании в IT-отрасли с легкостью повторяют и улучшают наиболее эффективные экономические модели развития бизнеса из традиционной экономики (в том числе связанные с конкурентными стратегиями объединения усилий с другими игроками рынка). Уровень интеграции компаний на локальных и глобальных рынках может плавно меняться от дружеского соседства до слияния. В данной статье рассмотрены примеры двух типов взаимодействия в IT-отрасли: партнерские программы и стратегические альянсы.

Конец прошлого столетия был ознаменован глобальным ростом востребованности подходов из маркетинга взаимодействий (relationship marketing $\mathrm{RM})$, подразумевающим активное взаимодействие производителя с окружающими его контрагентами [1] на всех этапах развития бизнеса. При этом понятие внутриотраслевой конкуренции стало еще более сложным: компании стали искать новые точки сотрудничества, развивая новые подходы к НИОКР, производству, сбытовой экспансии и даже найму персонала.

Во взаимодействии производителя с внешними контрагентами (конкурентами, участниками цепочки добавленной стоимости, потребителями) произошел качественный переход от строго имущественных отношений к целому набору различных экономических интеграций (в том числе виртуальных), которые можно представить следующим списком:

- неформальное сотрудничество (включая картельные сговоры);

• договорные отношения через посредника/потребителя/контрагента;

- разовые и долгосрочные партнерские программы;

- тактические и стратегические альянсы.
IT-отрасль как яркий представитель новой экономики, склонный к построению виртуальности во всех ее проявлениях, довольно быстро адаптировала данные экономические интеграции, приспособив их для решения ключевых задач в развитии бизнеса. Особенное внимание следует уделить таким формам сотрудничества, как партнерские программы широкого профиля и стратегические альянсы. Основная проблема, рассматриваемая в данной статье - это набор отраслевых особенностей, которые получили данные формы экономической интеграции в сфере информационных технологий (которые являются ярким примером новой экономики) в сравнении с такими же формами интеграции в традиционной экономике.

Так, в традиционной экономике партнерская программа - особый вид контрактных отношений, преследующий набор целей, одна из которых является основным мотивом сотрудничества. С точки зрения классического бизнес-анализа, партнерские программы - это продолжение реализации бизнес-процессов, требующих от компании взаимодействий с внешней средой: сбыт, наем персонала, маркетинговое продвижение. С точки зрения теории транзакционных издержек, в основе партнерских программ лежит идея минимизации издержек на контракты с поставщиками и использование разнообразных ресурсов, так как для предприятия выгоднее поддерживать взаимодействие с существующим кругом поставщиков (партнеров), избегая затрат как на поиск нужной информации, так и на заключение новых контрактов. Развитие партнерских программ в традиционной экономике неотрывно связано с такими понятиями, как аутсорсинг функций и вертикальная интеграция. Неслучайно самые первые широкие партнерские программы в XX в. были связаны с дистрибуцией товара, организацией производства и сбыта на определенных рынках.

Довольно часто на базе доминирующей идеи (цели) партнерских отношений происходит последовательное и формализованное углубление экономи- 
Таблица 1 / Table 1

Стратегические альянсы в традиционной экономике / Strategic alliances in the traditional economy

\begin{tabular}{|c|c|c|}
\hline № & Доминирующая цель & Примеры \\
\hline 1 & $\begin{array}{l}\text { Для обеспечения сбыта в различных } \\
\text { регионах мира }\end{array}$ & $\begin{array}{l}\text { Автомобильная промышленность (General Motors - АвтоВАЗ), } \\
\text { отрасли продуктов питания (Parmalat и локальные партнеры } \\
\text { в Бразилии, США, Украине) }\end{array}$ \\
\hline 2 & Для проведения НИОКР & $\begin{array}{l}\text { Фармацевтика (Pfizer - Medarex), автомобильная } \\
\text { промышленность (Renault - Nissan - АвтоBАЗ) }\end{array}$ \\
\hline 3 & $\begin{array}{l}\text { Сложные производства аппаратного } \\
\text { обеспечения в наукоемких отраслях } \\
\text { и разделение рисков в гигантских проектах }\end{array}$ & $\begin{array}{l}\text { Космическая промышленность (МКС, орбитальные обсерватории, } \\
\text { марсоходы), современная физика (станции детектирования } \\
\text { гравитационных волн, адронный коллайдер). } \\
\text { Стратегические атомные подлодки (предприятия военно- } \\
\text { промышленного комплекса и атомной промышленности) }\end{array}$ \\
\hline 4 & $\begin{array}{l}\text { Повышение удовлетворенности клиентов } \\
\text { отрасли }\end{array}$ & $\begin{array}{l}\text { Tранспортные компании (Star Alliance, SkyTeam и Oneworld). } \\
\text { Сфера гостеприимства (Global Hotel Alliance, Great Hotel } \\
\text { Organization) }\end{array}$ \\
\hline 5 & $\begin{array}{l}\text { Совместное регулирование стандартов для } \\
\text { новых рынков или новой продукции }\end{array}$ & $\begin{array}{l}\text { Холодный чай (PepsiCo - Lipton, Coca-Cola - Nestle). } \\
\text { Электронная коммерция в Китае (Wal-Mart - JD.com) }\end{array}$ \\
\hline 6 & Совместное поглощение конкурентов & $\begin{array}{l}\text { Поглощение компаний черной металлургии (Mittal Stee - } \\
\text { Arcelor). } \\
\text { Поглощение банков (Royal Bank of Scotland - Santander - Fortis) }\end{array}$ \\
\hline 7 & $\begin{array}{l}\text { Увеличение рыночной власти над } \\
\text { поставщиками и потребителями в отрасли }\end{array}$ & $\begin{array}{l}\text { Совместные закупки (Российский розничный альянс, Дрогери } \\
\text { Союз). } \\
\text { Услуги лизинга машин такси для частных лиц (Uber и различные } \\
\text { структуры Toyota) }\end{array}$ \\
\hline
\end{tabular}

Источник / Source: составлено авторами / compiled by the authors.

ческой интеграции в виде альянса корпораций. Стратегический альянс в традиционной экономике - это интеграция компаний сразу в нескольких ключевых бизнес-областях, максимальная по уровню до их слияния (поглощения). Классическое определение стратегического альянса в отечественной научной литературе подчеркивает, что объединение различных потенциалов (научного, кадрового, финансового, технологического) двух и более корпораций в формате стратегического альянса - это наиболее эффективный метод достижения поставленной цели [2]. В табл. 1 приведены наиболее типичные варианты стратегических альянсов по доминирующим целям и примеры из традиционной экономики.

Однако вслед за доминирующей целью, очевидной на этапе планирования стратегического альянса, довольно быстро возникают дополнительные. Экономическая интеграция углубляется, появляются первые результаты совместной работы, и становится возможным экономическое обоснование целесообразности слияния (поглощения).

Представляется интересным следующий набор синергетических явлений в стратегическом альянсе, подкрепленный экономическим планированием и управленческими усилиями:

- значительный рост экономической мощи для внешнего наблюдателя (потребителей, поставщиков, госорганов, кредитных учреждений и т.д.);

- эффект масштаба в использовании различных ресурсов;

- дополнительная степень гибкости при построении карьеры (удержании) для выдающихся сотрудников корпорации.

Российский опыт традиционной экономики в конце прошлого века показывал стремление компаний во множестве отраслей к «жесткой» интеграции в виде холдинговых структур. Причем это происходило не только вследствие силовых (рейдерских) захватов заводов, испытывающих существенные экономические проблемы, но и на добровольной основе, т.е. вопрос доверия к взаимодействию решался путем покупки предприятий и создания управляющих компаний. Однако в настоящее время ментальная неготовность к «мягким» формам интеграции в большей степени преодолена, а доверие между экономическими агентами может быть построено 
не только путем покупки контрольного пакета акций и концентрации власти в управляющей компании.

Между тем к началу XX в. IT-отрасль благополучно усвоила уроки традиционной экономики, включив различные варианты экономической интеграции в арсенал конкурентной борьбы на глобальном рынке. Однако и партнерские программы, и стратегические альянсы обладают серьезными отраслевыми особенностями, которые будут представлены в следующих разделах данной статьи.

\section{ПАРТНЕРСКИЕ ПРОГРАММЫ В IT-ОТРАСЛИ}

По аналогии с традиционной экономикой приведем набор классификаций партнерских программ в IT-отрасли: по ключевой цели и по типу взаимодействия. Важным экономическим аспектом, выделенным по данным типам партнерских программ, является характер и распределение затрат среди участников экономической интеграции. Среди ключевых целей партнерских программ в отрасли следует выделить представленные в табл. 2.

Рассмотрим мотивы и примеры партнерских программ по целям на примере отечественного и международного рынка информационных технологий. Так, совместный маркетинг на уровне партнерской программы обычно заключается в следующем наборе активностей:

- совместное проведение бизнес-мероприятий (разделение расходов и усилий, дополнение продуктами друг друга в надежде на комплексное удовлетворение запроса потенциальных клиентов);

- популяризация брендов, включая использование «отражения бренда» в совместных презентациях в сети Интернет, на бумажных проспектах и билбордах на выставках.

Наиболее яркие примеры таких программ можно увидеть у лидеров глобального IT-рынка с долгой историей: Microsoft, IBM, Dell и т.д. С одной стороны, эти компании десятилетиями выстраивают маркетинговую интеграцию с локальными партнерами, обеспечивая продвижение бренда (brand awareness) и демонстрируя локальным потребителям доступность глобальных системных технологий на локальном рынке. С другой стороны, локальные компании используют «отражение брендов» технологических гигантов, чтобы подчеркнуть солидность собственных программных и аппаратных решений, даже если фактически их ключевые технологии никак напрямую не связаны. Данный тип партнер- ства существенно экономит ресурсы участников, позволяя им в какой-то степени опираться в своей маркетинговой деятельности на бюджеты партнеров и экономию на масштабе.

Дистрибуция АО в IT-отрасли во многом схожа с любыми другими высокотехнологичными материальными продуктами. Однако дистрибуция ПО в IT-отрасли, с точки зрения отношений партнеров, очень отличается от партнерства в традиционной экономике в силу следующих обстоятельств:

1) необходимо преодолевать языковой барьер и проводить юридическую адаптацию ПО;

2) очевидны практически нулевые логистические издержки, а значит, низкие переменные расходы для всех участников сбыта;

3) присутствует чрезвычайно высокая маржинальность продаж.

Данные обстоятельства подталкивают вендора (производителя ПО) и дистрибутора совместно затратить существенные ресурсы для адаптации продукта и старта продаж, а потом стремительно увеличивать совместную прибыль до насыщения рынка. При этом транснациональные гиганты самостоятельно адаптируют свои продукты для локальных рынков, находят локальных партнеров и совместно первыми захватывают доминирующие позиции на рынке.

Ярким примером такого типа программ является Microsoft Partner Program, которая существует уже почти 30 лет и бюджет которой измеряется сотнями миллионов долларов. Операционные системы и пакеты офисных программ от Microsoft, благодаря чрезвычайно эффективной партнерской программе, заняли доминирующее положение во всем мире.

Несколько сложнее схожие процессы происходят при следующем типе партнерства, подразумевающем существенные работы по системной интеграции и внедрению ПО. В таком случае взаимодействие вендора и интегратора строится последовательностью издержек участников, изображенной на рисунке.

Наиболее впечатляющий успех по созданию партнерской программы такого типа продемонстрировала компания 1 , которая при собственном штате сотрудников в несколько сотен человек добилась широчайшей сети партнеров с проектами внедрения от Сахалина до Берлина. Компания 1C не использовала в развитии своего продукта какие-то уникальные подходы - похожим образом действовали все поставщики бухгалтерского ПО и отечественных ERP в конце 90-х гг. прошлого века. Вопреки маркетинговым представлениям об истории компании, описанным намного позднее реальных событий, 
Классификация партнерских программ в ІT-отрасли по целям / Classification of partnership programs in the IT industry by goals

\begin{tabular}{|c|c|c|}
\hline № & Цель & Комментарий \\
\hline 1 & Совместный маркетинг & $\begin{array}{l}\text { Как правило, партнерская программа связывает глобальные компании } \\
\text { широкого профиля (системные интеграторы, вендоры) с нишевыми } \\
\text { поставщиками. При этом нишевые поставщики в разработке своих } \\
\text { прикладных решений опираются на базовые технологии или знания } \\
\text { (опыт) глобальных партнеров }\end{array}$ \\
\hline 2 & $\begin{array}{l}\text { Дистрибуция программного (ПО) } \\
\text { и аппаратного (АО) обеспечения }\end{array}$ & $\begin{array}{l}\text { Самый частный тип партнерских отношений в отрасли: каждый } \\
\text { производитель ПО и АО создает сложный набор партнерских программ, } \\
\text { привлекая экономических агентов к участию в сбыте продукции }\end{array}$ \\
\hline 3 & $\begin{array}{l}\text { Внедрение ПО / Системная } \\
\text { интеграция }\end{array}$ & $\begin{array}{l}\text { Партнерская программа данного типа связывает производителей ПО } \\
\text { и АО с системными интеграторами, которые на основе базовых продуктов } \\
\text { поставщиков создают кастомизированные решения для корпоративных } \\
\text { потребителей }\end{array}$ \\
\hline 4 & $\begin{array}{l}\text { Совместные разработки базовых } \\
\text { технологий и прикладных } \\
\text { решений }\end{array}$ & $\begin{array}{l}\text { Партнерская программа объединяет производителей ПО и АО для } \\
\text { создания новых базовых технологий (например, блокчейн для } \\
\text { финтеха или стандарты мобильной связи) и завершенных прикладных } \\
\text { решений (например, смартфонов или автономных автомобилей). Такие } \\
\text { партнерские программы в случае успешного развития сотрудничества } \\
\text { довольно быстро переходят в стратегические альянсы }\end{array}$ \\
\hline 5 & Наем персонала & $\begin{array}{l}\text { Такие партнерские программы, как правило, объединяют крупные } \\
\text { IТ-компании и технологические университеты }\end{array}$ \\
\hline
\end{tabular}

Источник / Source: составлено авторами / compiled by the authors.

Разумные издержки вендора на создание документации и инструментов, упрощающих внедрение программного продукта / установку и интеграцию аппаратного обеспечения Высокие совместные издержки на обучения специалистов
интегратора

Высокие издержки вендора для организации консультаций и поддержки внедрения продукта

Незначительные издержки интегратора для организации обратной связи по продукту и процессам его внедрения у потребителей

Высокие издержки вендора и интегратора на организацию линий поддержки эксплуатации конечного решения у потребителя

Puc. / Fig. Издержки партнеров при совместном внедрении ПО и работам по системной интеграции / Partner costs for joint software implementation and system integration work.

Источник / Source: составлено авторами / compiled by the authors. 
ни собственный встроенный в продукт язык программирования, ни гибкая конфигурация систем, ни низкая цена для партнеров и потребителей не являлись уникальными атрибутами продуктов линейки 1С в России. Однако потрясающая скорость экспансии в продажах и масштаб партнерских программ позволили компании занять доминирующее положение во многих сегментах рынка ERP в CHГ, уничтожить локальных конкурентов и начать экспорт российского ПО в Европу.

Наиболее сложная в управлении и рискованная партнерская программа - это программа совместной разработки базовых технологий. Гигантские корпорации вкладывают значительные усилия в создание и унификацию технологии или готового продукта, который должен стать эталоном на рынке. Классический пример - это объединение усилий Mircosoft и IBM в разработке персональных компьютеров с операционной системой Windows. Однако еще интереснее более позднее объединение усилий компаний Intel, Microsoft, Philips, US Robotics (а чуть позже также - Hewlett-Packard, Alcatel-Lucent, NEC) в создании технологии и устройств USB и USB 2.0. Компании не просто выпустили новый разъем или базовую технологию, а навсегда изменили уровень универсальности устройств в персональных компьютерах. Отметим, что современные компьютеры (даже некоторые модели от компании Apple) всегда имеют USB-разъемы.

Ярким современным примером проекта, в котором партнеры пытаются освоить и формализовать технологию распределенных реестров хранения данных (блокчейн), является проект Hyperledger, в котором IBM, Intel и CISCO при минимальном участии других партнеров создают программно-аппаратные технологии, поддерживающие мировое распространение блокчейна в автоматизации промышленности и интернета вещей. Основная идея IBM, фактически инициировавшая данное партнерство - это установление стандартов технологии и отсечение «любых других блокчейнов» от следующей волны популярности данной технологии.

Наем персонала в IT-отрасли это сложнейшая проблема: хороших инженеров, маркетологов, продавцов в сфере информационных технологий мало, а хороших университетов, выпускающих их на трудовой рынок, еще меньше. Поэтому IT-компании включают технологические университеты в свои партнерские программы: транснациональные гиганты собирают лучших студентов со всего мира, локальные лидеры - в лучших университетах своей страны, рядовые IT-компании готовы создавать региональные офисы, чтобы трудоустраивать местных выпускников и становиться региональными центрами притяжения талантов. Так, российские компании Яндекс и Mail.Ru более 10 лет на разных уровнях образования (школы, лицеи, университеты) собирают таланты в области высоких технологий и точных наук [3], договорившись с ведущими школами страны: ВШЭ, МИФИ, МФТИ, СПбГУ и т.д. Затраты IT-компаний на такие партнерства незначительны и позволяют существенно экономить на найме персонала в сравнении со стратегиями зарплатных войн или «идеального офиса» (рабочего места).

Еще одну классификацию партнерских программ в IT-отрасли по типу взаимодействия можно построить, как показано в табл. 3.

Интернет-сервисы стали первым сектором ITотрасли, который сделал «реферальные» программы привлечения клиентов массовыми и назвал их партнерскими программами. Анализируя взаимодействие «партнеров», следует отметить, что данные программы являются псевдо-партнерскими и представляют собою сетевой маркетинг. Интернет-сервисы предлагают процент от прибыли (или скидку на свои услуги), получаемый с новых клиентов тем клиентам, которые их порекомендуют. При этом практически никаких издержек стороны не несут и практически не взаимодействуют, а значит, такое предложение может быть виртуальным, не подкрепленным юридическими формальностями, и - предложено максимальному кругу потенциально заинтересованных лиц.

Тип взаимодействия, подразумевающий обучение и контроль партнеров со стороны производителя, подразумевает, что его продукты достаточно просты в продаже, установке и обслуживании. Как правило, производитель организует учебный центр, а его партнеры выделяют в своем бизнесе специализированную практику, сотрудники которой занимаются продажей, установкой, обслуживанием программного и аппаратного обеспечения, поставляемого производителем. Производитель также организует линию поддержки и контроля эксплуатации продукции у конечных потребителей, создавая в том числе локальные офисы в странах присутствия. Такой тип взаимодействия требует значительных капитальных затрат производителя на ранних этапах создания партнерских программ, но позволяет экономить еще более существенные ресурсы, снижая переменные издержки при значительном расширении сбыта. В приведенных выше примерах партнерских прог- 


\section{Классификация партнерских программ в IT-отрасли по типу взаимодействия / Classification of partnership programs in the IT industry by type of interaction}

\begin{tabular}{|c|c|c|}
\hline № & Тип взаимодействия & Комментарий \\
\hline 1 & $\begin{array}{l}\text { «Реферальные» псевдо- } \\
\text { партнерские программы }\end{array}$ & $\begin{array}{l}\text { Широкое распространение в интернет-сервисах (по сути, это сетевой } \\
\text { маркетинг, когда прибыль с новых клиентов ІТ-сервиса делится с текущими } \\
\text { клиентами, которые подключили новых). Владелец сервиса затрачивает } \\
\text { минимальные усилия на обучение партнеров по «реферальным } \\
\text { программам» в виде унифицированных видеоуроков и инструкций }\end{array}$ \\
\hline 2 & Обучение и контроль & $\begin{array}{l}\text { Партнеры, организующие сбыт продукта производителя, и сам } \\
\text { производитель несут совместные затраты на этапе обучения основам сбыта } \\
\text { и обеспечивают контроль качества услуг и удовлетворенности клиента. Как } \\
\text { правило, производитель ПО и АО создает специализированный учебный } \\
\text { центр и службу внешнего контроля для реализации данных задач }\end{array}$ \\
\hline 3 & $\begin{array}{l}\text { Совместные проекты для } \\
\text { конечных потребителей }\end{array}$ & $\begin{array}{l}\text { Партнеры (как правило, вендор, интегратор и дистрибутор) несут } \\
\text { совместные затраты на всех этапах проекта: от сбыта до пост-продажного } \\
\text { обслуживания. При этом высокий уровень их интеграции в рамках проекта } \\
\text { является чрезвычайно важным для его успеха }\end{array}$ \\
\hline 4 & Совместное развитие & $\begin{array}{l}\text { Партнеры совместно развивают определенное направление бизнеса или } \\
\text { рынок. На разных стадиях процесса затраты и прибыли распределяются } \\
\text { между партнерами неравномерно, но ключевым фактором является } \\
\text { долгосрочность данного процесса. Данный тип партнерства в случае его } \\
\text { успешного развития, как правило, приводит к созданию стратегического } \\
\text { альянса }\end{array}$ \\
\hline
\end{tabular}

Источник / Source: составлено авторами / compiled by the authors.

рамм 1C и Microsoft данные компании смогли почти полностью перенести сбыт на локальных рынках на партнерские сети, поддерживаемые сетями учебных центров и локальными линиями поддержки на различных языках.

Однако более сложные внедрения у клиентов (например, ПО) или большие инфраструктурные проекты (например, строительство центра данных) требуют совместных усилий дистрибутора, интегратора и вендора. В данном типе партнерства все стороны в неравных долях несут издержки в течение всего проекта, успех которого напрямую зависит от слаженности их действий. Так, например, огромные российские компании КРОК и Техносерв создали и поддерживают партнерские отношения и линейки бизнеса по решениям всех ведущих мировых вендоров ПО (IBM, Oracle, Microsoft и т.д.) и производителей AO (IBM, Fujitsu, Intel, Siemens и т.д.).

Другой конкретный пример, объединяющий усилия двух российских компаний на рынке СНГ - это заключенное в 2016 г. партнерство между Terrasoft и ГК АйТи. Благодаря этому системный интегратор АйТи получил сравнительно недорогое и качественное решение для автоматизации бизнес-процессов маркетинга, продаж и сервиса от Terrasoft, а вендор расширил свои возможности по сбыту и осуществлению внедрений у заказчиков.

В совместных проектах (особенно для только появляющихся на рынке продуктов) каждый партнер выделяет специалистов на различные роли, и общая команда (с большей или меньшей степенью интеграции) должна достигнуть проектных целей. Хорошим примером из личной практики автора является внедрение IDM-решения в 2009 г. в крупном российском банке: к проектной команде системного интегратора (Инфосистемы Джет) были добавлены специалисты вендора и продавца решения (Sun Microsystems и IBM Россия и СНГ). Данное внедрение IDM-решения стало всего лишь четвертым в России, и были необходимы усилия всех партнеров, чтобы успешно завершить проект. Безусловно, в ходе проекта неоднократно возникали трения о распределении ролей и трудозатрат, однако, ни один из партнеров не демонстрировал оппортунистичный стиль поведения.

И, наконец, последний тип взаимодействия партнеров из табл. 3 направлен на совместное развитие в области продаж, освоения рынка, создания новых технологий. Партнеры несут серьезные совместные затраты на всех этапах долгосрочного сотрудниче- 
ства. Как правило, успешное партнерство в таком формате приводит с течением времени к образованию стратегического альянса или слиянию (поглощению). В качестве примера следует рассмотреть партнерские отношения поставщиков банковского ПO: IND Group (европейский лидер дистанционного банковского обслуживания) и MISYS (мировой лидер автоматизации казначейства). Обладая взаимодополняющими решениями для крупных банков, компании совместно участвовали в тендерах в Европе и совместно осваивали рынки Африки. После 4-х лет партнерства компания MISYS полностью купила компанию IND Group, сделав из нее несколько своих подразделений в Европе.

\section{СТРАТЕГИЧЕСКИЕ АЛЬЯНСЫ В ІТ-ОТРАСЛИ}

Ключевым различием между партнерскими (контрактными) отношениями и стратегическими альянсами в IT-отрасли являются уровень интеграции и сроки сотрудничества. При этом обмен опытом и знаниями между его участниками направлены на создание новой ценности для клиентов и дополнительные возможности извлечения прибыли. Довольно часто взаимодействие компаний в рамках партнерского соглашения с целью создания новых технологий и с типом взаимодействия «совместное развитие» перерастает в стратегический альянс (и далее, возможно, в слияние).

Стратегический альянс подразумевает наличие нескольких руководящих центров, а решения принимаются на основе диалога, не лишенного конфликтов и противоречий. При этом акцент смещен с конкуренции на сотрудничество между участниками.

Хорошей иллюстрацией является объявленный в 2016 г. стратегический альянс между крупными IT-компаниями Cisco и Salesforce. Salesforce является мировым лидером в области CRM [4], однако ключевые процессы взаимодействия с клиентами, автоматизируемые с помощью таких систем, переживают революционные изменения в течение последних 10 лет. Cisco также разрабатывает программные и аппаратные решения для взаимодействия с клиентами, объединенные в платформу Customer Success Platform. Обе компании, уходя от конкуренции, предпочитают создание стратегического альянса с целью «радикального повышения продуктивности бизнес-пользователей». Компании интегрируют собственные технологии и маркетинг таким образом, что платформа Cisco для совместной работы, интернета вещей и контакт-центров объединяется с приложениями CRM от Salesforce, занимая более прочное положение на конкурентном рынке и предлагая конечному потребителю более совершенное решение его бизнес-задач.

Как было показано в предыдущем разделе, некоторые типы партнерских отношений довольно схожи со стратегическими альянсами в традиционной экономике, однако, приведем ключевые различия:

- о создании стратегического альянса в IT-отрасли обязательно объявляется публично, это информационное сообщение многократно дублируется на всех рынках и инфо-площадках;

- в стратегических планах развития (бизнеспланах) организаций учитываются ресурсы союзника (кадровые, технологические, финансовые, интеллектуальные);

- стратегические альянсы направлены на достижение долгосрочных интересов участников.

Так, российские компании QIWI и 1С объявили в 2019 г. о стратегическим альянсе, построенном на развитии совместного программного продукта на базе «1C: Предприятие» для финтеха. Новый продукт направлен на типичную автоматизацию новых игроков финансового сектора, которые сейчас создают свои IT-решения самостоятельно. Альянс позволяет QIWI не создавать собственную ERP-систему с нуля, a 1C выйти на перспективный рынок финтеха, в котором у компании нет собственной экспертизы.

Аналогичным образом, американские IT-компании IBM и Docker в 2014 г. объявили о стратегическом партнерстве, которое позволило выпустить на рынок корпоративную версию Docker Hub Enterprise (DHE). Соединение маркетингового (сбытового) могущества с технологиями Docker позволило за 5 лет сделать из Docker де-факто технологический стандарт в отрасли (https://habr.com/ru/company/ flant/blog/326784). Компания Docker самостоятельно не смогла бы создать конкурентную службу сбыта по всему миру в короткие сроки, а IBM получила влияние на одну из прорывных технологий контейнеризации в разработке ПО и дополнительное решение в своем портфолио.

Доверие - это ключевой фактор построения стратегических альянсов, и существует набор инструментов, поддерживающих такое доверие и мешающих каждому из партнеров в реализации оппортунистического поведения:

- обмен миноритарными пакетами акций;

- совместное участие в общих органах, исполняющих контрольно-ревизионные, надзорные, управляющие и консалтинговые функции; 
- совместные базы знаний и постоянный обмен информацией на всех уровнях отношений.

- Заключение стратегического альянса обычно подразумевает формализацию в виде:

- договора (Партнерского Соглашения);

- создания совместной компании (филиала), подчиненной цели альянса.

Довольно часто создание стратегического партнерства или альянса - это первый шаг в реальной оценке компаний при слиянии и поглощении. История отрасли знает довольно много примеров, когда альянс завершался созданием нового бренда (Alcatel-Lucent, Finastra, Sony Ericsson $\mathrm{MC} \mathrm{AB).} \mathrm{Более} \mathrm{того,} \mathrm{для} \mathrm{некоторых} \mathrm{IT-компаний}$ поглощение со стороны более крупной компании является основной бизнес-целью с момента основания [5].

Интересным взглядом на стратегические альянсы представляется рассмотрение такой экономической интеграции со стороны риск-менеджмента. Как уже упоминалось выше, современная IT-отрасль развивается на высококонкурентном и быстроменяющемся глобальном рынке, на котором присутствуют как десятки тысяч нишевых игроков, так и крупные корпорации, чьи капитализации измеряются триллионами долларов, а обороты превышают годовые бюджеты многих развитых стран. Поэтому для средних и маленьких компаний в несколько сотен сотрудников является актуальной задача повышения стабильности в бизнесе. Элементом стратегии риск-менеджмента по повышению стабильности могут быть стратегические альянсы - это потенциальное накопление избыточных ресурсов внутри альянса (финансы, кадры, диверсификация сбыта, накопление специфического опыта).

\section{ОСОБЕННОСТИ ПОСТРОЕНИЯ ПАРТНЕРСКИХ ПРОГРАММ И АЛЬЯНСОВ В ІТ-ОТРАСЛИ}

В IT-отрасли существует огромный набор особенностей, которые существенным образом влияют на построение и развитие партнерских программ. Так, в части привлечения трудовых ресурсов следует отметить:

1) отрицательную безработицу;

2) недостаток / устаревание специфических навыков у специалистов на быстро меняющемся рынке;

3) высокие затраты компании на фонд оплаты труда специалистов.
В разрезе бизнес-процессов, связанных со сбытом, следует привести следующие специфические особенности:

1) настолько быстрое развитие и изменение виртуальных продуктов (ПО, интернет-сервисы), что даже их постоянные потребители не могут уследить за всеми изменениями;

2) значительные временные затраты на стороне потенциальных клиентов на принятие принципиального решения об использовании IT-услуг и продуктов;

3) быстрое вовлечение все новых и новых традиционных областей бизнеса в постоянное использование современных IT-продуктов (в процессах автоматизации, роботизации, цифровой трансформации и т.д.).

Совокупность данных двух наборов особенностей подталкивает многие IT-компании, предлагающие более-менее унифицированные продукты / услуги, к реализации функции сбыта компании через построение партнерских программ. Безусловно, компания не может обойтись без собственных продавцов, отлично разбирающихся в областях автоматизации и продуктах/услугах компании. Однако именно партнерские сбытовые программы позволяют при минимизации расходов увеличить присутствие бренда и предложения на различных рынках. Причем, в качестве сбытовых партнеров могут быть не только другие IT-компании, но и отраслевые консалтинговые компании и даже поставщики других отраслевых товаров и услуг.

Таким образом, высокие переменные затраты на фонд оплаты труда в сочетании с кросс-функциональностью многих ролей в ІТ-компаниях являются причинами создания партнерских программ в области сбыта с существенными отличиями:

- высокая степень открытости для новых участников вплоть до полной виртуализации отношений;

- гибкие условия сотрудничества;

- широкая поддержка партнеров в реализации клиентам продуктов друг друга.

Рассмотренные классификации партнерских программ и отраслевые особенности позволяют перейти в следующему определению Партнерской программы:

Партнерская программа в IT-отрасли - это объединение усилий нескольких компаний, направленное на достижение определенной цели при явном снижении текущих или потенциальных издержек всех участников.

Разработка новых технологий в IT-отрасли связана с высокой степенью неопределенности 
как в будущей коммерческой успешности, так и в итоговом уровне ценности для потребителей [6]. Партнерские отношения и стратегические альянсы, построенные на совместном создании новых ключевых технологий, могут оказаться чрезвычайно капиталоемкими и рискованными. Поэтому современные экономические интеграции такого рода в форме консорциумов или международных стратегических альянсов IT-компании сразу приглашают будущих потенциальных потребителей. Так, консорциум R 3 со штаб-квартирой в НьюЙорке разрабатывает с 2016 г. специализированное блокчейн-решение Corda для финансовых услуг (международные платежи, депозитарные операции и т.п.) и объединяет несколько команд блокчейнразработчиков и более 40 банков и финтех компаний из Европы, Америки и Азии: таким образом, производители и потребители данного решения делят риски и инвестиции в разработке технологии.

В России Сбербанк в соответствии с концепциями цифрового банкинга в различных формах (инвестиции, партнерские отношения, альянсы, совместные компании) участвует в развитии практически всех перспективных технологий: искусственного интеллекта (с Яндекс и Mail.ru), обработки больших данных (c GridGain Systems), цифровых трансформаций традиционного бизнеса (c FoodPlex) и т.д.

Еще одна особенность данных экономических интеграций в IT-отрасли - это чрезвычайно быстрый переход от партнерских отношений и альянсов к слиянию (поглощению) как в России, так и в мире. Так, в традиционной экономике Россия в начале XXI в.это один из лидеров в мире по количеству слияний и поглощений, связанных с построением вертикально интегрированных федеральных холдингов в промышленности и финансового-промышленных групп. В это время в мире уже нарастало количество более «мягких» типов экономической интеграции в виде альянсов и партнерских отношений. В современном мире IT-отрасль с ее высоким уровнем конкурентной борьбы довольно быстро переняла такие модели: количество стратегических альянсов давно обогнало по количеству отрасли традиционной экономики [7]. При этом значительное количество таких альянсов переросло в слияние (поглощение) компаний, а соответствующее положительное решение принимается в IT-отрасли чрезвычайно быстро. При этом характер таких стратегических альянсов не всегда подразумевает успешное процветание обеих компаний в рамках экономической интеграции. Вот несколько примеров.
В 2009 г. российская компания «Амфора-Групп» и российский филиал австрийской S\&T International прошли путь от стратегического альянса к недружественному поглощению всего за три месяца.

Компания Google в 2008 г. объявила об альянсе с вполне успешной компанией Motorola, которая выбрала операционную систему Android для своих смартфонов. Через 3 года компания Motorola была разделена на две части: подразделения, разрабатывающие мобильные телефоны и телекоммуникационное оборудование, стали частью компании Google.

Печально известен стратегический альянс национальной гордости Финляндии - Nokia и транснационального гиганта Microsoft, заключенный в 2011 г. В 2013 г. наиболее известная линейка бизнеса Nokia по выпуску мобильных телефонов и соответствующего ПО была выкуплена корпорацией Microsoft по «шокирующе низкой цене». Компания Nokia из компании № 1 в мире по продаже мобильных телефонов (2004-2011 гг.) превратилась просто в компанию с самым дорогим брендом в Финляндии.

Основной причиной такого быстрого принятия решения о слиянии (поглощении) в IT-отрасли являются высокий уровень прозрачности финансовых показателей и необходимость быстрого принятия решений в условиях глобальной конкурентной борьбы.

\section{ЗАКЛЮЧЕНИЕ}

IT-отрасль стремительно переняла и преобразовала «под себя» типичные для традиционной экономики формы экономической интеграции. При этом в таких партнерских отношениях, альянсах и консорциумах есть набор своих отраслевых особенностей.

Основными особенностями таких экономических интеграций в IT-отрасли являются:

1) высокий уровень открытости и виртуализации для средних и малых компаний;

2) агрессивная политика наращивания формализованных альянсов для крупных компаний по всем направлениям развития бизнеса;

3) высокая скорость принятия решений о развитии отношений: партнерские отношения альянс - поглощение (слияние).

Партнерские отношения и стратегические альянсы всегда имеют одну и более доминирующих целей, их участники находятся в том или ином типе взаимоотношений, выражающемся в структуре совместных затрат. Ключевым конкурентным преимуществом в отрасли является правильное выстраивание партнерских отношений, позволяющее, с одной 
стороны, обеспечить быстрый и глобальный рост бизнеса, сохранить необходимые запасы (резервы) на случай неудачного развития ситуации, а, с другой стороны - не допустить недружественное и невыгодное поглощение более сильным партнером. При этом партнерские отношения и альянсы остаются в IT-отрасли наиболее цивилизованным способом продажи компании по достойной цене, позволяя правильно оценивать реальную стоимость бизнеса. Таким образом, стратегическая активность в создании партнерских отношений и альянсов повышает шансы IT-компаний, заложивших в своем развитии соответствующие цели, на коммерчески удачные сделки по слиянию и поглощению.

\section{СПИСОК ИСТОЧНИКОВ/REFERENCES}

1. Gordon I. Relationship Marketing: New Strategies, Techniques and Technologies to Win the Customers You Want and Keep Them Forever. John Wiley and Sons Publishers; 1999.

2. Лучко М.Л. Конкурентные стратегии транснациональных компаний в 90-е гг. XX - начале XXI в. М.: Экономический факультет МГУ, ТЕИС; 2004. 256 с.

Luchko M.L. Competitive strategies of transnational companies in the 90s of the XX-early XXI century. Moscow: Moscow State University, TEIS; 2004. (In Russ.).

3. Луганская Д. Почему «Яндекс» и Mail.ru Group обучают потенциальных конкурентов. URL: https://www. rbc.ru/business/27/04/2015/552c5e8f9a7947afc7624d3d.

Luganskaya D. Why Yandex and Mail.ru train potential competitors. URL: https:/www.rbc.ru/business/27/04/ 2015/552c5e8f9a7947afc7624d3d. (In Russ.).

4. Clarke, Gavin (2013) Salesforce boots SAP from customer-wrangling software top slot. SaaS outsold onpremises in 2012, says Gartner. The Channel Register. The Register.

5. Пащенко Д.С. Влияние модели бизнеса софтверной компании на модель ее производственных процессов на примере региона Центральной и Восточной Европы. Мир новой экономики. 2017;(1):70-78.

Paschenko D.S. Influence of the business model of a software company on the model of its production processes on the example of the region of Central and Eastern Europe. Mir novoi ekonomiki = The World of the New Economy. 2017;(1):70-78. (In Russ.).

6. Комаров Н.М., Пащенко Д.С. Современная высокотехнологичная компания в ІТ-отрасли: краткий обзор. Вестник Евразийской науки. URL: https://esj.today/PDF/58SAVN 419.pdf.

Komarov N.M., Pashchenko D.S. Modern high-tech company in the IT industry: A brief overview. Bulletin of Eurasian science. URL: https://esj.today/PDF/58SAVN 419.pdf. (In Russ.).

7. Prahalad C.K., Hamel G. The Core Competence of the Corporation. Harvard Business Review. 1990;3(68):79-91.

\section{ИНФОРМАЦИЯ ОБ АВТОРАХ}

Денис Святославович Пащенко - кандидат технических наук, независимый консультант в области разработки программного обеспечения, Москва, Россия

denpas@rambler.ru

Николай Михайлович Комаров - доктор экономических наук, профессор, ФГУП «ЦНИИ «ЦЕНТР», научный консультант, Москва, Россия

nikolai_komarov@mail.ru

\section{ABOUT THE AUTHORS}

Denis S. Paschenko - Cand. Sci. (Eng.), an independent consultant in the field of software development, Moscow, Russia denpas@rambler.ru

Nikolay M. Komarov - Dr Sci. (Econ.), consultant in CNII Center, Moscow, Russia nikolai_komarov@mail.ru

Статья поступила 10.10.2019; принята к публикации 10.11.2019.

Авторы прочитали и одобрили окончательный вариант рукописи.

The article received on 10.10.2019; accepted for publication on 10.11.2019.

The authors read and approved the final version of the manuscript. 